\title{
Subcoracoid impingement and subscapularis tendon: is there any truth?
}

\author{
Leonardo Osti ${ }^{1}$ \\ Francesco Soldati ${ }^{2}$ \\ Angelo Del Buono ${ }^{1}$ \\ Leo Massari² \\ ${ }^{1}$ Unit of Arthroscopic and Sports Medicine, Hesperia \\ Hospital, Modena, Italy \\ 2 Unit of Orthopaedics and Traumatology, University \\ of Ferrara, Italy
}

Corresponding author:

Leonardo Osti

Unit of Arthroscopy and Sports Medicine

Hesperia Hospital

Via Arquà, $80 / a$

41125 Modena, Italy

e-mail: leonardoosti@yahoo.com

\section{Summary}

Subcoracoid impingement and stenosis have been described related to anterior shoulder pain and subscapularis tendon tears, but the pathogenesis and related treatment of this condition has still not been explained properly. Variability of coracoid morphology has been described and both traumatic and iatrogenic factors can modify it. Some authors referred this to a primary narrow coracohumeral distance with different threshold values defined as increased risk factor for subscapularis and antero-superior RC tear; opposite theories stated that the stenosis is secondary to an anterosuperior translation of the humeral head toward the coracoid due to degenerative changes of the rotator cuff tendons. Limited coracoplasty can be performed when related risk factors are identified; however no clear consensus arises from specific literature review and extensive clinical and instrumental examination of the patient should be performed in order to identify specific risk factors for subscapularis tendon pathology and, subsequently, tailor the proper approach.

KEY WORDS: subcoracoid impingement, coracohumeral space, subcoracoid stenosis, coracoplasty.

\section{Introduction}

Impingement of the lesser tubercle of the humerus (LTH) against the coracoid process (CP) is source of shoulder pain ${ }^{1}$. This condition also known as subcoracoid (SC) impingement may be present in association with subcoracoid stenosis. This latter is characterized by decreased coracohumeral distance on axial and oblique sagittal views, and a variable spectrum of rotator cuff pathology 2 varying from a state of massive tear to anterosuperior tears of the cuff including the subscapularis tendon ${ }^{3-5}$.

On the other hand, other authors state that subcoracoid impingement and massive rotator cuff tears concur when the humeral head translates anteriorly and superiorly toward the coracoid, and the coracohumeral space is reduced 6,7 .

This study aims to report about the scientific evidence on subcoracoid impingement and to ascertain whether it may be predisposed to anatomical features, biomechanics of the shoulder and connected joints, and subscapularis tendon pathology.

Diagnosis: history, clinical examination, imaging

\section{Anatomy and etiology}

The role of anatomic configuration has been described as a predisposing factor for SC impingement. The coracoacromial interval includes the acromion, the coracoacromial ligament, and the tip of the coracoid process. Although the coracoacromial interval involves acromion, $\mathrm{CHL}$, and coracoid process, it is the latter that is considered most responsible for altering the volume and shape of the coracoacromial arch. In a cadaveric study ${ }^{8}$, it has been reported that the coracoid localizes, on average, to the 1:47-o'clock position of the glenoid and $21.5 \mathrm{~mm}$ from the nearest portion of the labrum. Renoux et al. ${ }^{9}$ showed that in most cases a variation in the height and length of the coracoid process is responsible for altering the space between the coracoacromial arch and the rotator cuff. In an anatomical morphometric study, Gumina et al. ${ }^{10}$ described three different configurations of the coracoid process and the coracoglenoid space, of which Type I, occurring in $45 \%$ of the scapulae, presents the lowest mean values of the coracoglenoid angle and coracoid overlap. That implies a short coracohumeral distance as a predisposing factor for coracohumeral impingement. However, this configuration cannot be directly related to an idiopathic subcoracoid impingement thus other authors suggest an investigation of this space through a conventional CT scan ${ }^{11}$.

Subcoracoid impingement can be classified as idiopathic, traumatic or iatrogenic. Idiopathic means re- 
lated to congenital abnormalities of the coracoid laterally projecting more than usual, calcification or ossification of the subscapularis tendon ${ }^{12-14}$ or subscapularis muscle hypertrophy ${ }^{15}$, ganglion cysts ${ }^{16,17}$. Traumatic causes include humeral head and neck fractures, displaced humeral or scapular fractures and malunions ${ }^{18-20}$, posterior sternoclavicular dislocation $^{21}$. Surgical procedures around the shoulder can alter the relationship between the coracoid and lesser tuberosity, leading to impingement. Both Bristow/ Latarjet and Trillat procedure have been described to possibly produce a subcoracoid impingement ${ }^{18}$. An increased anteversion of the glenoid neck, after posterior glenoid osteotomy, can lead to an increased coracoglenoid angle and a decreased coracohumeral distance, thus predisposing to impingement ${ }^{22}$. Finally, subcoracoid stenosis may be related to minor anterior instability ${ }^{23}$ or rotator cuff insufficiency and sick scapula syndrome, which can produce an anterosuperior translation of the humeral head ${ }^{24-26}$. The anterosuperior translation of the humeral head leads to a decrease in the coracohumeral distance. Performing an anterior acromioplasty in a case of an insufficient function of the rotator cuff and a narrow coracohumeral space, the anterosuperior migration of the humeral head would induce the subcoracoid impingement syndrome ${ }^{5,6}$.

\section{Clinical diagnosis and intrumental exams}

In subcoracoid impingement the patient has frequently a history of chronic overuse and multiple episodes of microtrauma in overhead activities with the shoulder in a forward-flexion, adducted and internally rotated position, such as in driving a car, in drawing on a blackboard, or in the follow-through phase of throwing ${ }^{27}$. The main symptom is a non specific dull pain in the anterior aspect of the shoulder that can often be referred to the upper arm and to the forearm. It is exacerbated by movements in forward-flexion, adduction and internal rotation. In iatrogenic syndromes, patients suffer from postoperative severe pain often associated with paresthesia which never corresponds with the sensory area of a cervical root or a peripheral nerve. Range of motion is limited in horizontal adduction and internal rotation 28 .

Physical examination need to detect any deformities in the shoulder area and previous scars. It often reveals tenderness of the soft tissues around the coracoid process or between the coracoid and the lesser tuberosity. The coracoid impingement test is similar to the Kennedy-Hawkins impingement sign, except that the patient's shoulder is placed in a position of cross arm adduction, forward elevation, and internal rotation to bring the lesser tuberosity in contact with the coracoid ${ }^{18}$. Elevation is most painful between $80^{\circ}$ and $130^{\circ}$, rather than in full motion as in subacromial impingement; abduction to $90^{\circ}$ combined with internal rotation is limited and painful as well as horizontal cross-adduction similar to cross arm test for AC joint ${ }^{28}$. Subcoracoid infiltration of local anesthetics can relieve the pain and help to establish the diagnosis, but the validity and accuracy of this test has been questioned. Clinical evaluation of the subscapularis functions through the most reliable tests described, such as Napoleon, Belly-press, lift off and Bear hug tests, as well as the evaluation of passive pathological external rotation should be performed 29 .

Standard radiographic AP and axillary views perpendicular to the plane of the scapula can detect abnormalities of the bony elements, which narrow the coracohumeral space. Some authors also suggest the supraspinatus outlet view for a chevron-shaped coracoid process, which is a synonymous with coracoid impingement ${ }^{30}$.

Magnetic resonance imaging or CT scans are useful for further delineating coracoid and subcoracoid anatomy $27,31-33$. It is important to evaluate coracohumeral distance in both the axial and sagittal views in patients presenting with subscapularis tears, especially if surgical intervention is planned ${ }^{2}$. Kinematic, or cine, MRI may be used to evaluate the dynamic aspects of subcoracoid impingement ${ }^{27}$.

A CT axial view can be used to evaluate the coracoid index, a measurement of the lateral projection of the coracoid beyond a line tangential to the articular surface of the glenoid; Dines et al. ${ }^{18}$ reported its mean value in 67 normal shoulders to be $8.2 \mathrm{~mm}$.

The measurement of the coracohumeral interval is another way to quantify anatomic variation in this region. The coracohumeral interval or distance is defined as the minimal distance between the coracoid process and lesser tuberosity, as measured on an axial MRI scan with the humerus in maximum internal rotation ${ }^{34}$. Using MRI to measure the coracohumeral interval, some authors found that asymptomatic patients averaged $11 \mathrm{~mm}^{27}$, with none less than $4 \mathrm{~mm}$, in maximal internal rotation. By contrast, the mean coracohumeral interval in symptomatic patients was $5.5 \mathrm{~mm}$, and it appears to narrow with internal rotation. The average coracohumeral interval for females was $3 \mathrm{~mm}$ smaller than that for males ${ }^{31}$. Friedman et al. ${ }^{27}$ also noted that there is no redundancy of the subscapularis tendon in asymptomatic subjects with the arm in full internal rotation. Patients with subcoracoid impingement often demonstrate increased soft tissue in the subcoracoid space because of redundancy or folding of the subscapularis tendon and capsular tissues when the shoulder is in this provocative position of maximum internal rotation. Other changes such as edema located at the ACP level, a subscapular tendon injury, changes in the rotator interval, thickening of the coracoacromial ligament and the clavipectoral fascia, as well as the reduction in the coracoid index, may be shown by MRI. However, sensitivity of the internal rotation position in detecting coracoid impingement on $\mathrm{MRI}$ is only $5,3 \%$ with specificity $97,6 \%$; this suggest that coracoid impingement appears to be largely a clinical diagnosis that may be supported or suggested, but not established, by $M R I^{31}$. Anyway, as subcoracoid impingement could be a cause of persistent shoulder pain following 
supraspinatus repair ${ }^{6}$, signs of this condition on preoperative MRI may be the necessary clue in leading to a thorough arthroscopic examination of the subscapularis-coracoid relationship, which may ultimately lead to the decision to perform a subcoracoid decompression ${ }^{35}$.

Friedman et al. ${ }^{27}$ assessed the $\mathrm{CHI}$ in 50 asymptomatic volunteers and 75 patients with symptomatic shoulders, all of whom underwent a cine MRI of the shoulder using a shoulder-rotating device. They support that cine MRI provides valuable information on the subcoracoid region not obtainable with other imaging modalities. However, this technique is not widely available. Additionally, it seems unlikely that this would be a cost-effective diagnostic option, especially in cases of bilateral shoulder involvement.

Giaroli et al. ${ }^{32}$ compared preoperative MRI scans in a group of 19 patients with demonstrable coracoid impingement at the time of surgery with a control group, to determine whether the $\mathrm{CHI}$ acquired from routinely performed MRI can diagnose coracoid impingement reliably; the study showed a low sensitivity of MRI, so the authors concluded that this imaging technique could support this clinical diagnosis, but not establish it.

Ultrasonography has also been shown to be a valuable, easily available and less cost-effective method to image the subcoracoid recess and diagnose coracoid impingement in a recent study by Tracy et al. ${ }^{36}$; a significant difference has been found between the $\mathrm{CHI}$ in normal asymptomatic shoulders and the $\mathrm{CHI}$ in shoulders with symptoms consistent with coracoid impingement. Additionally, the use of sonography could improve diagnostic evidence and provide effective symptomatic relief to patients by accurately delivering a dose of a local anesthetic to the affected site. Tra$\mathrm{cy}^{36}$ showed that, with appropriate training and equipment, sonography could play a role in the diagnosis of coracoid impingement by showing a narrowing of the $\mathrm{CHI}$ in symptomatic patients, but inter-observer reliability and validity of this technique has not been proved.

\section{Treatment}

Indication for treatment arises from careful evaluation of the patient with a resistant or recurrent subcoracoid impingement syndrome ${ }^{18-20,23,28}$; clinical investigation should functionally evaluate the shoulder for possible muscular imbalance, capsular contracture and scapular dyskinesis, which should be else addressed 26

Mechanical volume expanding anatomical changes such as calcification or ossification of the subscapularis tendon ${ }^{12-14}$, ganglion cysts ${ }^{16,17}$, previous humeral head and neck fractures, displaced humeral or scapular fractures and malunions ${ }^{18-20}$, or changes of coracoid orientation due to surgical procedures can be all candidate for coracoplasty ${ }^{18,28}$.

Coracoplasty can be addressed either with open or arthroscopic techniques ${ }^{3,18,18,37}$. As far as open ap- proaches are concerned, Dines et al. ${ }^{18}$ described a simple osteotomy of the neck of the coracoid process to change its angle by bending it medially, adding the cutting of the outer $1,5 \mathrm{~cm}$ of the coracoid tip, performed through a deltopectoral incision dissecting the lateral insertion of the conjoined tendon. The tendon is finally either reinserted on the remaining coracoid base or repaired side-to-side more medially. Gerber et al. ${ }^{28}$ suggested a combination of resection of the coracoacromial ligament, acromioplasty and conjoined tendon resection, because they believed that isolated coracoid impingement was rare.

Arthroscopic treatment of coracoid impingement can be also performed; the coracoid and subcoracoid space should be thoroughly examined in patients with long head biceps and biceps reflection pulley tears, subscapularis tears, and anterior supraspinatus tears because of the high association with coracohumeral impingement ${ }^{3,37}$.

Capsulolabral lesions or laxity should also be detected in order to choose the best treatment ${ }^{23}$. A careful examination of subscapularis insertion footprint can be carried out by appropriate manipulation of the arm in abduction and internal rotation in order to avoid missing a partial tear of the tendon. The long head biceps tendon must be evaluated dynamically by rotating the arm in internal and external rotation for subluxation, which is commonly associated with subscapularis tears. Tears or degeneration of the tendon $>50 \%$ of its thickness and/or lesions of the biceps pulley system must be addressed biceps tenodesis ${ }^{3}$ or tenotomy.

Then the coracohumeral space must be evaluated for subcoracoid stenosis. Authors agree with the definition of subcoracoid stenosis, when the coracohumeral space is less than $6 \mathrm{~mm}^{5,38,39}$. To diagnose subcoracoid impingement, one must show direct contact of the coracoid against the lesser tuberosity in an impingement position, bringing the arm into a combination of flexion, adduction and internal rotation; if the coracoid impacts the humerus the test is positive ${ }^{22}$.

The coracoplasty could be performed by a trans-articular approach ${ }^{40}$ (through the rotator interval) or an extra-articular ${ }^{41}$ approach from an anterolateral subacromial portal. An intact subscapularis is essential to allow an appropriate orientation of the coracoplasty 40 . Outcome studies detailing this relatively rare diagnosis are limited, but authors typically report reasonable outcomes for both open and arthroscopic procedures $^{3,4,18-20,23,28,37,40,41}$.

\section{Discussion}

Few studies have been performed about coracoid impingement and criteria for diagnosis and treatment of this pathologic condition are still controversial and not well defined. The lack of high- level studies on this subject doesn't allow to properly define the treatment of choice and makes it difficult to find guidelines on diagnostic and therapeutic options. 
Lo $^{40}$ and Karnaugh ${ }^{41}$ reported satisfactory results obtained by arthroscopic excision of the posterolateral border of the coracoid process through different portals (portal for the scope) to visualize the coracoid process.

The intra-articular approach provides several advantages ${ }^{40}$. First, the posterolateral aspect of the coracoid is easily palpated and approached through the rotator interval. Furthermore, it allows a direct assessment of the prominence of the coracoid process, the space available for the subscapularis tendon, and the coracohumeral space; the ability to resect the coracoid in line with the insertion of the subscapularis tendon and the lesser tuberosity; an easy assessment of decompression. Although resection of the rotator interval may theoretically increase instability, only a small portion of the rotator interval and postoperative instability has not been found. ${ }^{37}$ Finally, as far as the positioning of the patient during surgery is concerned, a dynamic cadaver study showed that the lateral cord moved closer to the coracoid process at $60^{\circ}$ $(14,4 \mathrm{~mm})$ than at $30^{\circ}$ of abduction under traction during simulated shoulder arthroscopy position using the lateral decubitus position; the margin of safety for lateral cord injury during arthroscopic surgery around the coracoid process is improved with lower abduction angles in the lateral decubitus position ${ }^{42}$.

\section{Conclusion}

Subcoracoid impingement has been reported as a cause of anterior shoulder pain and may result in severe subscapular tears and tendinopathy. In our review of literature we have found only Level IV evidence studies and the described data are controversial and don't permit to try conclusions on diagnostic and therapeutic criteria. Large multicenter prospective trials will be necessary to explain the issue and the outcomes of the different operative techniques.

\section{References}

1. Goldthwait JE. An anatomic and mechanical study of the shoulder joint, explaining many of the cases of painful shoulder, many of the recurrent dislocations and many of the cases of brachial neuralgias or neuritis. Am J Orthop Surg 1909; 6:579-606.

2. Li X, Fallon J, Egge N, Curry EJ, Patel K, Owens BD, Busconi BD. MRI study of associated shoulder pathology in patients with full-thickness subscapularis tendon tears. Orthopedics 2013; 36(1):e44-50.

3. Lo IKY, Burkhart SS. The etiology and assessment of subscapularis tears: A case for subcoracoid impingement, the roller-wringer effect, and the TUFF lesions of the subscapularis. Arthroscopy 2003; 19:1142-1150.

4. Richards DP, Burkhart SS, Campbell SE. Relation between narrowed coracohumeral distance and subscapularis tears. Arthroscopy 2005; 21(10):1223-1228.

5. Park JY, Lhee SH, Oh KS, Kim NR, Hwang JT. Is arthroscopic coracoplasty necessary in subcoracoid impingement syndrome? Arthroscopy 2012; 28(12):1766-1775.
6. Suenaga N, Minami A, Kaneda K. Postoperative subcoracoid impingement syndrome in patients with rotator cuff tear. J Shoulder Elbow Surg 2000; 9:275-278.

7. Ben Kibler BW, Sciascia A. What went wrong and what to do about it: pitfalls in the treatment of shoulder impingement. Instr Course Lect 2008; 57:103-112.

8. Tham A, Purchase R, Kelly JD 4th. The relation of the coracoid process to the glenoid: an anatomic study. Arthroscopy 2009; 25(8):846-848.

9. Renoux S, Monet J, Pupin P, Collin M, Apoil A, Gasc JP, Jouffroy FK, Doursounian L. Preliminary note on biometric data relating to the human coraco-acromial arch. Surg Radiol Anat 1986; 8(3):189-195.

10. Gumina S, Postacchini F, Orsina L, Cinotti G. The morphometry of the coracoid process-its aetiologic role in subcoracoid impingement syndrome. Int Orthop 1999; 23(4):198201.

11. Kleist KD, Freehill MQ, Hamilton L, Buss DD, Fritts H. Computed tomography analysis of the coracoid process and anatomic structures of the shoulder after arthroscopic coracoid decompression: a cadaveric study. J Shoulder Elbow Surg 2007; 16(2):245-250.

12. Arrigoni P, Brady PC, Burkhart SS. Calcific tendonitis of the subscapularis tendon causing subcoracoid stenosis and coracoid impingement. Arthroscopy 2006; 22(10):1139.e1-3.

13. Franceschi F, Longo UG, Ruzzini L, Rizzello G, Denaro V. Arthroscopic management of calcific tendinitis of the subscapularis tendon. Knee Surg Sports Traumatol Arthrosc 2007; 15(12):1482-1485.

14. Peidro L, Serra A, Suso S. Subcoracoid impingement after ossification of the subscapularis tendon. J Shoulder Elbow Surg 1999; 8(2):170-171.

15. Schöffl V, Schneider H, Küpper T. Coracoid impingement syndrome due to intensive rock climbing training. Wilderness Environ Med 2011; 22(2):126-129.

16. Terabayashi N, Fukuta M, Ito $\mathrm{Y}$, Takigami I, Nishimoto $\mathrm{Y}$, Shimizu K. Shoulder impingement syndrome due to a ganglion cyst below the coracoacromial ligament: a case report. J Bone Joint Surg Am 2011; 93(8):e36.

17. Ko JY, Shih $\mathrm{CH}$, Chen WJ, Yamamoto R. Coracoid impingement caused by a ganglion from the subscapularis tendon. A case report. J Bone Joint Surg Am 1994; 76(11):17091711.

18. Dines DM, Warren RF, Inglis AE, Pavlov H. The coracoid impingement syndrome. J Bone Joint Surg Br 1990; 72:314-316.

19. Patte D. The subcoracoid impingement. Clin Orthop 1990; 254:55-59.

20. Kowalsky MS, Bell JE, Ahmad CS. Arthroscopic treatment of subcoracoid caused by lesser tuberosity malunion: a case report and review of the literature. J Shoulder Elbow Surg 2007; 16(6):e10-14.

21. Yel M, Parham M, Burkhead WZ Jr. Old unreduced posterior sternoclavicular dislocation and coracoid impingement. Proc (Bayl Univ Med Cent) 2001; 14(3):243-245.

22. Freehill MQ. Coracoid impingement: diagnosis and treatment. J Am Acad Orthop Surg 2011; 19(4):191-197.

23. Garofalo R, Conti M, Massazza G, Cesari E, Vinci E, Castagna A. Subcoracoid impingement syndrome: a painful shoulder condition related to different pathologic factors. Musculoskelet Surg 2011; 95 Suppl 1:S25-29.

24. Kibler WB, Dome D. Internal impingement: concurrent superior labral and rotator cuff injuries. Sports Med Arthrosc 2012; 20(1):30-33.

25. Kibler WB, Sciascia A, Wilkes T. Scapular dyskinesis and its relation to shoulder injury. J Am Acad Orthop Surg 2012 20(6):364-372.

26. Kibler WB, Ludewig PM, McClure PW, Michener LA, Bak K, Sciascia AD. Clinical implications of scapular dyskinesis in 
shoulder injury: the 2013 consensus statement from the 'scapular summit'.

27. Friedman RJ, Bonutti PM, Genez B. Cine magnetic resonance imaging of the subcoracoid region. Orthopedics 1998; 21:545-548.

28. Gerber C, Terrier F, Ganz R. The role of the coracoid process in the chronic impingement syndrome. J Bone Joint Surg Br 1985; 67:703-708.

29. McFarland EG, Selhi HS, Keyurapan E. Clinical evaluation of impingement: what to do and what works. Instr Course Lect 2006; 55:3-16.

30. Kragh JF Jr, Doukas WC, Basamania CJ. Primary coracoid impingement syndrome. Am J Orthop (Belle Mead NJ) 2004; 33(5):229-232.

31. Apoil A. Antero-internal impingement of the shoulder. Ann Radiol (Paris) 1992; 35(3):161-166.

32. Giaroli EL, Major NM, Lemley DE, Lee J. Coracohumeral interval imaging in subcoracoid impingement syndrome on MRI. AJR Am J Roentgenol 2006; 186(1):242-246.

33. Bonutti PM, Norfray JF, Friedman RJ, Genez BM. Kinematic MRI of the shoulder. J Comput Assist Tomogr 1993; 17(4):666-669.

34. Hekimoğlu B, Aydın H, Kızılgöz V, Tatar IG, Ersan O. Quantitative measurement of humero acromial, humero-coracoid, and coraco-clavicular intervals for the diagnosis of subacromial and subcoracoid impingement of shoulder joint. Clin Imaging 2013; 37(2):201-210.
35. Mulyadi E, Harish S, O'Neill J, Rebello R. MRI of impingement syndromes of the shoulder. Clin Radiol 2009; 64(3):307318.

36. Tracy MR, Trella TA, Nazarian LN, Tuohy CJ, Williams GR. Sonography of the coracohumeral interval: a potential technique for diagnosing coracoid impingement. J Ultrasound Med 2010; 29(3):337-341.

37. Gaskill TR, Braun S, Millett PJ. Multimedia article. The rotator interval: pathology and management. Arthroscopy 2011 27(4):556-567.

38. Lo IK, Parten PM, Burkhart SS. Combined subcoracoid and subacromial impingement in association with anterosuperior rotator cuff tears: An arthroscopic approach. Arthroscopy 2003; 19(10):1068-1078.

39. Nové-Josserand L, Boulahia A, Levigne C, Noel E, Walch G. Coracohumeral space and rotator cuff tears. Rev Chir Orthop Reparatrice Appar Mot 1999; 85:677-683.

40. Lo IK, Burkhart SS. Arthroscopic coracoplasty through the rotator interval. Arthroscopy 2003; 19(6):667-671.

41. Karnaugh RD, Sperling JW, Warren RF. Arthroscopic treatment of coracoid impingement. Arthroscopy 2001; 17(7):784787.

42. Pan WJ, Teo YS, Chang HC, Chong KC, Karim SA. The relationship of the lateral cord of the brachial plexus to the coracoid process during arthroscopic coracoid surgery: a dynamic cadaveric study. Am J Sports Med 2008; 36(10):1998-2001. 